\title{
Enhanced TOA Estimation Using OFDM over Wide-Band Transmission Based on a Simulated Model
}

\author{
Huthaifa A. Obeidat ${ }^{1}$ (D) . Imran Ahmad ${ }^{2}$. Mohammad R. Rawashdeh ${ }^{3}$. \\ Ali A. Abdullah ${ }^{2}$ - Wafa S. Shuaieb ${ }^{4}$. Omar A. Obeidat ${ }^{5} \cdot$ Raed A. Abdallhameed $^{2,6}$
}

Accepted: 20 October 2021 / Published online: 31 October 2021

(c) The Author(s) 2021, corrected publication 2021

\begin{abstract}
This paper presents the advantages of using a wideband spectrum adopting multi-carrier to improve targets localization within a simulated indoor environment using the Time of Arrival (TOA) technique. The study investigates the effect of using various spectrum bandwidths and a different number of carriers on localization accuracy. Also, the paper considers the influence of the transmitters' positions in line-of-sight (LOS) and non-LOS propagation scenarios. It was found that the accuracy of the proposed method depends on the number of sub-carriers, the allocated bandwidth (BW), and the number of access points (AP). In the case of using large BW with a large number of subcarriers, the algorithm was effective to reduce localization errors compared to the conventional TOA technique. The performance degrades and becomes similar to the conventional TOA technique while using a small BW and a low number of subcarriers.
\end{abstract}

Keywords Indoor localization · OFDM · Time of arrival · Wideband spectrum

\section{Introduction}

Orthogonal Frequency Division Multiplexing (OFDM) has emerged in recent years as an effective digital modulation technique that is at the heart of all major wireless standards used or in development today, such as the 4G Long-Term Evolution (LTE), Wi-Fi IEEE 802.11a, WiMAX and in Digital Video Broadcasting (DVB) systems [1-3].

OFDM is utilized in several communication systems due to its robustness to multipath channels and high transmission rate in wireless communications networks. However, for

Huthaifa A. Obeidat

h.obeidat@jpu.edu.jo

1 Faculty of Engineering, Jerash University, Jerash, Jordan

2 Faculty of Engineering and Informatics, University of Bradford, Bradford, UK

3 Faculty of Engineering, Yarmouk University, Irbid, Jordan

4 Faculty of Engineering Omar, Al-Mukhtar University, Al Beida, Libya

5 College of Engineering, Wayne State University, Detroit, MI, USA

6 Basra University College of Science and Technology, Basra 61004, Iraq 
reliable signal transmission, the OFDM technique requires precise timing and accurate frequency synchronization $[4,5]$. Other key disadvantages of OFDM are Inter-Symbol Interference (ISI) and Inter-Carrier Interference (ICI) [6].

ICI often occurs as a result of the loss of synchronization caused by frequency offset and time offset between oscillators at the transmitter and receiver's end, which in effect results in the orthogonality, so the transmitted signal cannot be completely separated at the receiver. Thus, ICI decreases the signal-to-noise ratio (SNR) and increases error probability $[7,8]$.

Moreover, a large peak-to-average power ratio caused by the superposition of all subcarrier signals becomes a distortion problem [9]. The desirous advantages of OFDM have motivated its application for improved localization of targets, to provide accurate mobile station (MS) positioning within both outdoor and indoor environments.

Authors in [10] used the OFDM-Time of Arrival (TOA) algorithm for position estimation of a Long Term Evolution (LTE) signal. A similar algorithm was proposed to detect the arrival times of Wi-Fi signals [11, 12]. In [13], a simple OFDM-TOA-based algorithm is proposed to estimate the Direct Path (DP). Similar research was conducted in [14], by combining path detector to interference cancellation it becomes possible to distinguish low-power DP from the nearby interference.

TOA localization can be done using lateration [15]. Each time measurement between target and access point (APs) leads to a distance estimation, by having three or more APs, the target's location can be inferred [16]. Localization using TOA has the advantage of being highly accurate, however; it is sensitive to multipath and the existence of direct path [17]. Also, precise synchronization between APs is required and the availability of huge bandwidth (BW) is important for accurate estimations [18]. TOA detection techniques can be classified into four main categories: correlation-based techniques [19], maximum likelihood techniques [20], subspace techniques [21], and inverse Fourier transform techniques [19].

This paper introduces a coded OFDM system to be used in the application of localization systems and enhance the TOA estimation over the wideband transmission. The localization of objects within the indoor environment is investigated over a wide-band spectrum using the multi-carrier OFDM modulation technique. It is attended that the large bandwidth can support the time resolution required to estimate the localized positions of the objects. Of course with the advantages that have been added by the OFDM, the whole process can improve the estimation accuracy compared to conventional methods applied to similar applications [22-25]. In this study, a fractional spectrum of the lower Ultra-Wideband (UWB) was utilized to mitigate the effects of indoor channel propagations due to the high number of multipath, in which several carriers are spread over the bandwidth based on the impulse response of the channels using Wireless-InSite (WI) and then suitable estimations of time arrivals are applied, followed by a numerical technique to estimate the position of the hidden objects.

The organization of the paper is as follows: the second section presents a mathematical model for TOA estimation, while in the third section, the simulated model is illustrated. Results and discussion are introduced in Sect. 4, and finally, conclusions are drawn in Sect. 5.

\section{Mathematical Model of OFDM for Time of Arrival Estimation}

The idea is to use simple lateration localization, based on TOA; however, time is estimated based on analyzing the OFDM signal. Starting with the OFDM system, given that the input signal $g(t, \omega)$ is [6]: 


$$
g(t, \omega)=e^{j 2 \pi f t}
$$

where $f$ and $t$ are frequency and time respectively. Assuming a linear time-invariant channel, the output can be simplified as:

$$
s(t, \omega)=e^{j 2 \pi f t} \sum_{k=1}^{n} a_{k} e^{j \varphi_{k}} e^{-j 2 \pi f \tau_{k}}=e^{j 2 \pi f t} U(2 \pi f)
$$

where $a_{k}, \varphi_{k}, \tau_{k}$ and $n$ are the $k t h$ multipath attenuation, phase shift, propagation delay, and the number of multipath rays, respectively. The spectrum bandwidth is divided by $N$ subcarriers, the $j$ th frequency sample can be expressed by:

$$
f_{j}=\frac{B}{2}\left(-1+(j-1) \frac{2 n}{N}\right)
$$

And the $j$ th uniform frequency sample of $U(2 \pi f)$ is given by:

$$
U\left(2 \pi f_{j}\right)=\sum_{k=1}^{n} a_{k} e^{j \varphi_{k}} e^{-j 2 \pi f_{j} \tau_{k}}
$$

The sampling time is given by:

$$
\Delta t=\frac{1}{B}=\frac{1}{N \cdot \Delta f}
$$

The challenge is how to utilize the benefits of using the OFDM system in localization. Before proceeding into this point, it's worth mentioning that we have extracted the channel information through simulations that were conducted in WI software at $5 \mathrm{GHz}$. We first extracted the arrival rays' corresponding information including phase, time delay, and received signal strength. This information is taken to a MATLAB code which has three functions.

Firstly, the code constructs the OFDM system based on Eqs. 1-5. The code allows the user to select $N$ and BW. After that, the $N$-inverse transform of the received signal is estimated. The inverse fast Fourier transform (IFFT) translates frequency domain data to timedomain samples, i.e. from the discrete frequency domain we can have discrete time-domain samples.

By choosing a sufficient number of subcarriers and wider BW, it is possible to have more resolution on time ( $\Delta t$ is less than the time between multipath). We then mapped the high-resolution time with the output of the IFFT, after that we choose the time with the highest value of IFFT as the TOA, which is the second task of the code, in other words, the TOA is estimated based on the mapping between the discrete-time domain samples with the highest output of the IFFT.

In the third task, the code performs localization by using the lateration technique based on Eqs. 6-11.

For an electromagnetic wave, the elapsed time and travel distance are related by the speed of light, given the TOA, the distance between the transmitter and receiver is estimated.

Assuming we have several receiver points with known locations, and a transmitter with an unknown location, the TOA readings can be used to find the relative distances between the transmitter and each receiver, thus, by using lateration, it is possible to find the transmitter's location [20]. 
Lateration can be solved using the linear least square technique, which is helpful especially for Non-line-of-sight (NLOS) propagation [20]:

$$
\frac{1}{R} \sum_{i=1}^{R} d_{i}^{2}=\frac{1}{R} \sum_{i=1}^{R}\left[\left(\hat{x}-x_{i}\right)^{2}+\left(\hat{y}-y_{i}\right)^{2}\right]
$$

where $d_{i}$ and $R$, are the distance between the $i^{\text {th }}$ receiver and transmitter and the number of receivers respectively, $\left(x_{i}, y_{i}\right)$ is the $i^{\text {th }}$ receiver coordinates and $(\hat{x}, \hat{y})$ are the estimated transmitter coordinates. Rearranging Eq. 6 for the $l$ th receiver:

$$
\begin{aligned}
& {\left[y_{l}-\frac{1}{R} \sum_{i=1}^{R} y_{i}\right] \hat{y}+\left[x_{l}-\frac{1}{R} \sum_{i=1}^{R} x_{i}\right] \hat{x}} \\
& =0.5\left(\left[y_{l}^{2}-\frac{1}{R R} \sum_{i=1}^{R} y_{i}^{2}\right]+\left[x_{l}^{2}-\frac{1}{R} \sum_{i=1}^{R} x_{i}^{2}\right]-\left[d_{l}^{2}-\frac{1}{R} \sum_{i=1}^{R} d_{i}^{2}\right]\right)
\end{aligned}
$$

For all receivers, a matrix can be represented as $(\boldsymbol{A} z=\boldsymbol{b})$ where $\left(z=\left[\begin{array}{l}\hat{y} \\ \hat{x}\end{array}\right]\right)$

$$
\begin{gathered}
\boldsymbol{A}=\left(\begin{array}{c}
y_{1}-\frac{1}{R} \sum_{i=1}^{R} y_{i} x_{1}-\frac{1}{R} \sum_{i=1}^{R} x_{i} \\
\cdot \\
y_{R}-\frac{1}{R} \sum_{i=1}^{R} y_{i} x_{R}-\frac{1}{R} \sum_{i=1}^{R} x_{i}
\end{array}\right) \\
\boldsymbol{b}=\left(\begin{array}{c}
0.5\left(\left[y_{1}{ }^{2}-\frac{1}{R} \sum_{i=1}^{R} y_{i}^{2}\right]+\left[x_{1}{ }^{2}-\frac{1}{R} \sum_{i=1}^{R} x_{i}^{2}\right]-\left[d_{1}{ }^{2}-\frac{1}{R} \sum_{i=1}^{R} d_{i}^{2}\right]\right) \\
\cdot \\
0.5\left(\left[y_{R}{ }^{2}-\frac{1}{R} \sum_{i=1}^{R} y_{i}{ }^{2}\right]+\left[x_{R}{ }^{2}-\frac{1}{R} \sum_{i=1}^{R} x_{i}{ }^{2}\right]-\left[d_{R}{ }^{2}-\frac{1}{R} \sum_{i=1}^{R} d_{i}^{2}\right]\right)
\end{array}\right)
\end{gathered}
$$

Then, the transmitter location can be estimated as:

$$
Z=\left(A^{T} A\right)^{-1} A^{T} b
$$

The position error is calculated by estimating the Euclidean distance [26]:

$$
\text { Error }=\sqrt{(x-\hat{x})^{2}+(y-\hat{y})^{2}}
$$

where $(x, y)$ is the transmitter's true coordinates.

\section{Simulation Model}

The scenario environments were created using WI software. WI is a site-specific radio propagation software that provides user-requested outputs for different indoor and outdoor environments and has the ability to provide efficient and accurate predictions of channel propagation characteristics like received signal strength, propagation paths, complex impulse response, delay spread, and time of arrival/departure, etc. [27]. The 
software has been validated over the WLAN frequencies [28, 28]. The obtained channel response is to be used with the OFDM multi-subcarrier system for our proposed localization method.

The simulated model represents the 3rd floor of the Chesham building at the University of Bradford. The transmitter was placed in three locations.

Four receivers were distributed at fixed known locations and mounted $1.5 \mathrm{~m}$ above the floor. The transmitter was placed in both line-of-sight and NLOS with the receivers as were seen in Fig. 1. Coordinates of all transmitters and receivers are listed in Table 1. Transmitter and receivers' antennas used were omnidirectional and the operating frequency was $5 \mathrm{GHz}$ with $2 \mathrm{GHz}$ bandwidth. Settings for the Wireless InSite model are given in Table 2.

Table 3 shows the complex impulse response received at Rx-1 with 10 multipath over the desired band including the LOS path. By convolving the channel impulse response with the OFDM multi-subcarriers spread over the bandwidth, the proposed TOA is estimated by taking the inverse fast Fourier Transform (IFFT) of the convolution. The maximum TOA is used to infer the transmitter's location.

The conventional TOA simply uses the arrival times of the path which are the values in the "Time" column in Table 3 for distance estimations.

In this analysis, the range of the adopted bandwidth is $(50 \mathrm{MHz}, 100 \mathrm{MHz}, 250 \mathrm{MHz}$, $500 \mathrm{MHz}, 1 \mathrm{GHz}$, and $2 \mathrm{GHz})$ while the number of subcarriers ranges are $(16,32,64$, 256, 512, 1024, and 2048).

Fig. 1 The layout of all transmitters and receivers

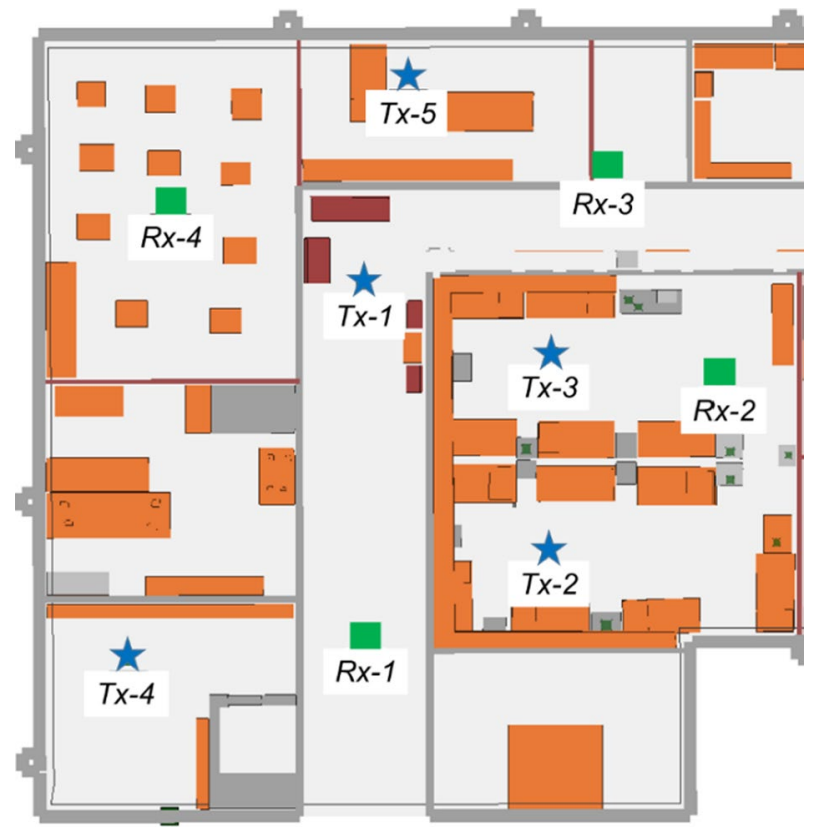


Table 1 Access Points locations

Table 2 Wireless InSite settings for the investigated scenario

\begin{tabular}{ll}
\hline Access Point & Coordinates $(x, y, z)$ in meter \\
\hline$R x-1$ & $(4.5,4.1,1.5)$ \\
$R x-2$ & $(12.659 .99,1.5)$ \\
$R x-3$ & $(10,14.86,1.5)$ \\
$R x-4$ & $(0.04,14.13,1.5)$ \\
$T x-1$ & $(4.43,12.25,1.5)$ \\
$T x-2$ & $(8.72,6.11,1.5)$ \\
$T x-3$ & $(8.8,10.64,1.5)$ \\
$T x-4$ & $(-0.97,3.62,1.5)$ \\
\hline
\end{tabular}

\begin{tabular}{ll}
\hline Setting & Value \\
\hline Transmitter antenna & Omnidirectional \\
Receiver antenna & Omnidirectional \\
Operating frequency & $5 \mathrm{GHz}$ \\
Bandwidth & $2 \mathrm{GHz}$ \\
Number of reflections & 6 \\
Number of transmissions & 4 \\
Number of diffractions & 0 \\
Ray-spacing & $0.2^{0}$ \\
Maximum rendered paths & 10 \\
Ray-tracing method & Shooting-and- \\
& Bouncing-Rays \\
Ray-tracing acceleration & (SBR) \\
Propagation model & Octree \\
\hline
\end{tabular}

Table 3 Complex impulse response output

\begin{tabular}{lcll}
\hline Multipath No & Phase $\left({ }^{\circ}\right)$ & Time $(\mathrm{s})$ & Power $(\mathrm{dBm})$ \\
\hline 1 & 114.813 & $2.72 \mathrm{E}-08$ & -39.187 \\
2 & -150.495 & $2.80 \mathrm{E}-08$ & -41.601 \\
3 & -45.266 & $2.89 \mathrm{E}-08$ & -42.755 \\
4 & 176.807 & $2.90 \mathrm{E}-08$ & -42.839 \\
5 & 119.707 & $2.97 \mathrm{E}-08$ & -44.696 \\
6 & -16.269 & $2.98 \mathrm{E}-08$ & -44.875 \\
7 & -76.84 & $4.22 \mathrm{E}-08$ & -51.444 \\
8 & -80.377 & $4.33 \mathrm{E}-08$ & -51.991 \\
9 & 74.659 & $4.27 \mathrm{E}-08$ & -52.404 \\
10 & 169.951 & $4.34 \mathrm{E}-08$ & -53.459 \\
\hline
\end{tabular}




\section{Results and Discussion}

In general, the accuracy of the TOA localization depends greatly on the available BW and the number of receivers. The accuracy of the proposed method depends on the number of sub-carriers and the allocated BW. Comparing to the conventional TOA (the first

Table 4 Transmitter at the $3^{\text {rd }}$ location (Tx-3) LE in meters using the proposed approach with a different number of receivers

\begin{tabular}{|c|c|c|c|c|c|c|}
\hline BW (MHz) & $\begin{array}{l}\text { No. of subcar- } \\
\text { riers }\end{array}$ & $\begin{array}{l}\text { Receiv- } \\
\text { ers }(1,2 \text {, } \\
3,4)\end{array}$ & $\begin{array}{l}\text { Receivers }(1, \\
2,3)\end{array}$ & $\begin{array}{l}\text { Receiv- } \\
\text { ers }(1, \\
2,4)\end{array}$ & $\begin{array}{l}\text { Receivers }(2 \text {, } \\
3,4)\end{array}$ & $\begin{array}{l}\text { Receiv- } \\
\text { ers }(1 \text {, } \\
3,4)\end{array}$ \\
\hline \multirow[t]{8}{*}{2000} & 2048 & 0.97 & 3.32 & 1.56 & 2.99 & 0.02 \\
\hline & 1024 & 0.97 & 3.31 & 1.56 & 2.98 & 0.03 \\
\hline & 512 & 0.96 & 3.3 & 1.56 & 2.96 & 0.03 \\
\hline & 256 & 0.95 & 3.27 & 1.56 & 2.92 & 0.05 \\
\hline & 128 & 0.74 & 10.55 & 4.94 & 9.61 & 0.35 \\
\hline & 64 & 7.7 & 8.72 & 7.29 & 9.28 & 7.53 \\
\hline & 32 & 6.13 & 7.03 & 5.71 & 7.68 & 6.01 \\
\hline & 16 & 6.53 & 7.17 & 6.21 & 7.7 & 6.45 \\
\hline \multirow[t]{7}{*}{1000} & 1024 & 1.01 & 3.91 & 1.89 & 3.53 & 0.26 \\
\hline & 512 & 1.06 & 3.67 & 1.89 & 3.16 & 0.28 \\
\hline & 256 & 0.99 & 3.41 & 1.56 & 3.12 & 0.06 \\
\hline & 128 & 0.97 & 3.35 & 1.56 & 3.03 & 0.02 \\
\hline & 64 & 0.94 & 3.23 & 1.57 & 2.86 & 0.1 \\
\hline & 32 & 7.57 & 8.56 & 7.16 & 9.12 & 7.4 \\
\hline & 16 & 5.98 & 6.66 & 5.64 & 7.2 & 5.9 \\
\hline \multirow[t]{6}{*}{500} & 512 & 0.62 & 2.94 & 1.18 & 2.94 & 0.32 \\
\hline & 256 & 0.61 & 2.91 & 1.19 & 2.89 & 0.31 \\
\hline & 128 & 0.59 & 2.85 & 1.2 & 2.81 & 0.31 \\
\hline & 64 & 0.98 & 4.19 & 1.89 & 3.95 & 0.33 \\
\hline & 32 & 0.94 & 3.93 & 1.93 & 3.58 & 0.44 \\
\hline & 16 & 7.45 & 8.48 & 7.02 & 9.09 & 7.29 \\
\hline \multirow[t]{5}{*}{250} & 256 & 1.33 & 4.4 & 1.95 & 4.06 & 0.22 \\
\hline & 128 & 1.3 & 4.33 & 1.95 & 3.97 & 0.17 \\
\hline & 64 & 1.25 & 4.19 & 1.95 & 3.78 & 0.09 \\
\hline & 32 & 1.18 & 3.93 & 1.96 & 3.41 & 0.17 \\
\hline & 16 & 0.67 & 2.67 & 0.69 & 3.05 & 0.69 \\
\hline \multirow[t]{4}{*}{100} & 128 & 1.92 & 1.51 & 2.41 & 3.9 & 3.2 \\
\hline & 64 & 1.83 & 1.56 & 2.28 & 3.93 & 3.11 \\
\hline & 32 & 2.03 & 2.1 & 2.02 & 2.11 & 2.02 \\
\hline & 16 & 1.52 & 1.53 & 1.52 & 1.53 & 1.52 \\
\hline \multirow[t]{3}{*}{50} & 64 & 5.39 & 7.21 & 3.36 & 11.56 & 6.66 \\
\hline & 32 & 5.38 & 7.21 & 3.39 & 11.41 & 6.57 \\
\hline & 16 & 5.37 & 7.21 & 3.46 & 11.14 & 6.41 \\
\hline $\begin{array}{l}\text { Conventional } \\
\text { TOA }\end{array}$ & 6.57 & 7.20 & 6.24 & 7.75 & 6.49 & \\
\hline
\end{tabular}


Fig. 2 The estimated position of Tx-1, using $2 \mathrm{GHz}$ and $\mathrm{BW}=256$ subcarriers
Fig. 3 The estimated position of Tx-2, using $1 \mathrm{GHz}$ and $\mathrm{BW}=512$ subcarriers
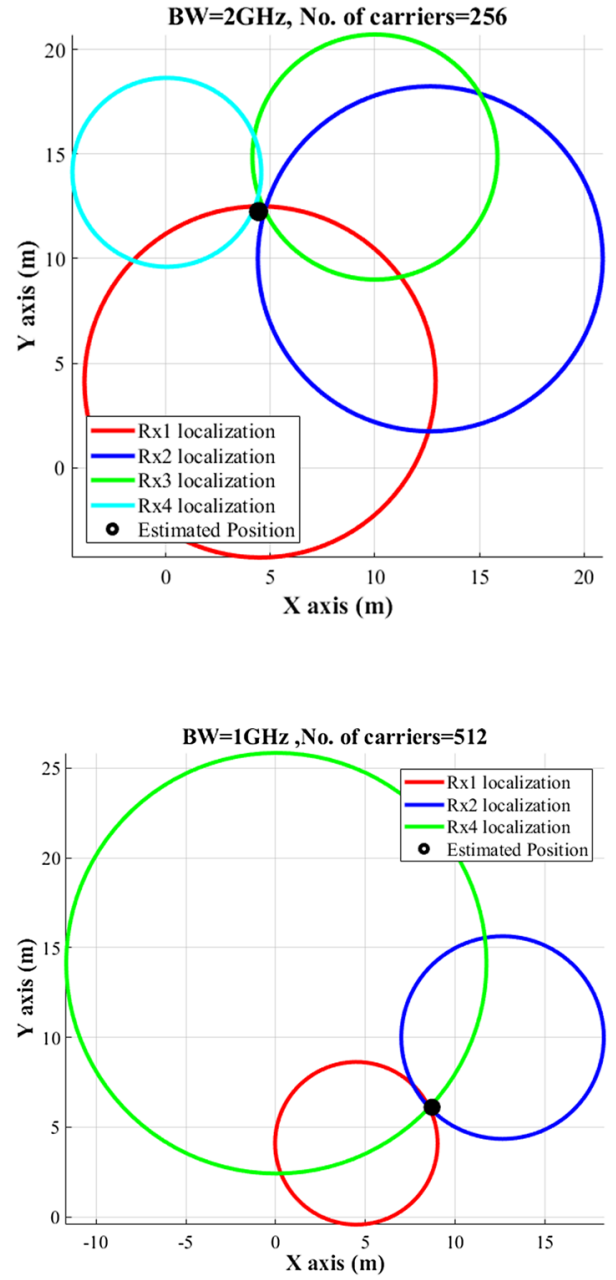

path arrival time), this approach minimized the error to centimeters.

As seen in Table 4, when we used 4-receivers with $2 \mathrm{GHz}$ BW and 2048 sub-carriers, the localization error (LE) was $0.97 \mathrm{~m}$. Using the same settings with 3 receivers, LE was $3.32 \mathrm{~m}$. Those results are still better than the conventional TOA results, where LE were $6.67 \mathrm{~m}$ using four receivers and $7.2 \mathrm{~m}$ using receivers. As seen, LE using the proposed algorithm was reduced compared to the conventional TOA approach.

In most cases, the average localization error using the proposed method was decreased to around $2 \mathrm{~m}$ for Tx-1, $3.32 \mathrm{~m}$ for Tx-2, and $4.03 \mathrm{~m}$ for Tx-3, while utilizing different sets of bandwidths and subcarriers. However, at low bandwidth and low number of subcarriers, the error increases to become approximately the same value as the conventional TOA approach as presented in Table 4.

Figure 2 shows the estimated position of Tx-1 using 4-receivers with $2 \mathrm{GHz}$ BW and 256 subcarriers. In this case, LE was $0.354 \mathrm{~m}$ which is $2 \mathrm{~m}$ less than the conventional TOA LE. Figure 3 presents Tx-2 localization using 3- receivers (Rx-1, Rx-2, Rx-3) with $1 \mathrm{GHz}$ BW and 512 subcarriers where the LE was $0.1555 \mathrm{~m}$. 
Fig. 4 The estimated position of Tx-3, using $250 \mathrm{MHz}$ and $\mathrm{BW}=16$ subcarriers

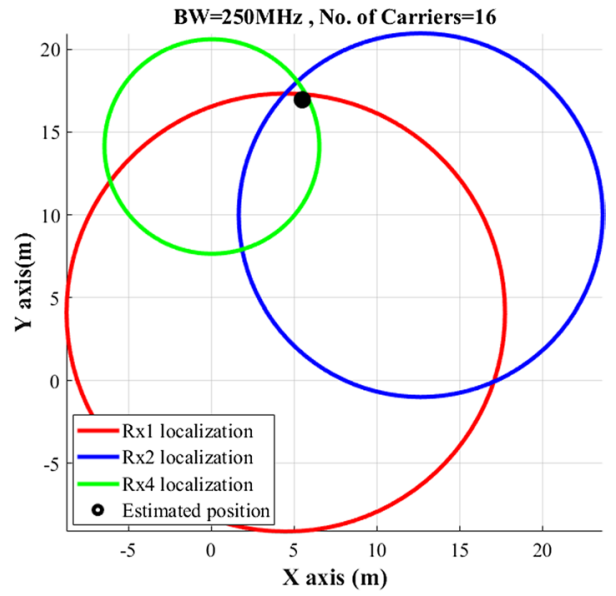

Figure 4 demonstrates the estimated position of Tx-3 using 3- receivers ( $R x-1, R x-2$, Rx-4) with $250 \mathrm{MHz}$ BW and 16 sub-carriers. The LE was $0.6946 \mathrm{~m}$ which is $5.5 \mathrm{~m}$ less than the conventional TOA localization error.

Figure 5 shows the LE values when estimating transmitter at location 1 using $2 \mathrm{GHz}$ BW and various subcarriers. As seen, most LEs of the proposed algorithm are less than the minimum conventional TOA LE except for the 16 carriers case. The maximum LE values in the proposed method occurred when the number of subcarriers was 16, however; it remains less than the maximum value of the LE of the traditional method.

\section{Conclusions}

This paper describes the OFDM technique for wireless communications and desirous advantages of OFDM to improve the localization of targets, in order to provide accurate mobile station (MS) positioning within indoor environments, and provided an overview of different delimiting factors that affect the performance and capability of OFDM. The causes and effects of these drawbacks and the various methods to deal with these problems for improved performance of OFDM systems are covered in the paper.

The localization of objects within the indoor environment over a wideband spectrum adopting multi-carrier has been presented. The utilized proposed algorithm to estimate

Fig. 5 The error values of the estimated Tx-1 position using the proposed algorithm

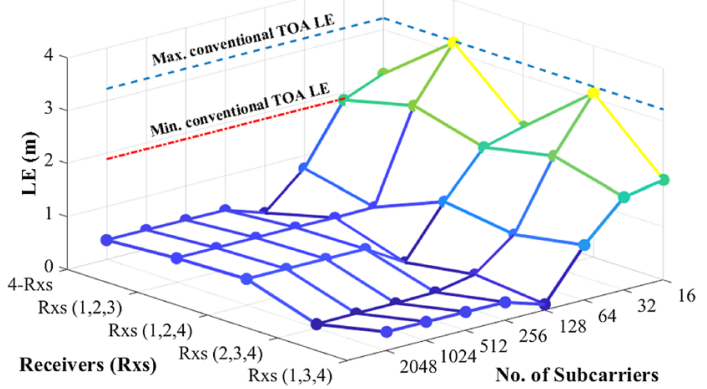


the position of several transmitter positions was also presented. The method was based on the TOA for various spectrum bandwidths and the number of carriers covering the LOS and the NLOS positions of the transmitter's positions. The method adopted the impulse response of the channel to estimate the transmitter position. It was concluded that the TOA approach over several wide bandwidths and different subcarriers was effective to reduce the localization errors compared to the typical TOA technique.

Data Availability Data are available upon request from the author.

\section{Declarations}

Conflict of interest The authors declare that they have no known competing financial interests or personal relationships that could have appeared to influence the work reported in this paper.

Open Access This article is licensed under a Creative Commons Attribution 4.0 International License, which permits use, sharing, adaptation, distribution and reproduction in any medium or format, as long as you give appropriate credit to the original author(s) and the source, provide a link to the Creative Commons licence, and indicate if changes were made. The images or other third party material in this article are included in the article's Creative Commons licence, unless indicated otherwise in a credit line to the material. If material is not included in the article's Creative Commons licence and your intended use is not permitted by statutory regulation or exceeds the permitted use, you will need to obtain permission directly from the copyright holder. To view a copy of this licence, visit http://creativecommons.org/licenses/by/4.0/.

\section{References}

1. Bhardwaj, M., Gangwar, A., \& Soni, D. (2012). A review on OFDM: Concept, scope \& its applications. IOSR Journal of Mechanical and Civil Engineering, 1(1), 7-11.

2. Cho, Y. S., Kim, J., Yang, W. Y. and Kang, C. G. (2010). MIMO-OFDM wireless communications with MATLAB. Wiley.

3. Hanzo, L., Münster, M., Choi, B., and Keller, T. (2005) OFDM and MC-CDMA for broadband multiuser communications, WLANs and broadcasting. Wiley

4. Leria, V. J. and Lohan, E.-S. (2012). Timing-based location estimation for OFDM signals with application in LTE, WLAN and WIMAX. In 2012 International Conference on Localization and GNSS, pp. $1-5$.

5. Mensing, C. (2013). Location determination in OFDM based mobile radio systems. Technische Universität München.

6. Tse and, D., Viswanath, P. (2005). Fundamentals of wireless communication. Cambridge university press.

7. Aziz, W., Ahmed, E., Abbas, G., Saleem, S., \& Islam, Q. (2012). Performance analysis of carrier frequency offset (CFO) in OFDM using MATLAB. Journal of Engineering, 1(1), 5-10.

8. Altaf, F., Shah, S., Shahjehan, W., and Khan, H. (2017). ICI Suppression in OFDM Systems for LTE.

9. Hwang, T., Yang, C., Wu, G., Li, S., \& Li, G. Y. (2008). OFDM and its wireless applications: A survey. IEEE Transactions on Vehicular Technology, 58(4), 1673-1694.

10. Wang, P., \& Morton, Y. (2020). Performance comparison of time-of-arrival estimation techniques for LTE signals in realistic multipath propagation channels. Journal of the Institute of Navigation, 67(4), 691-712.

11. Bialer, O., Raphaeli, D., \& Weiss, A. J. (2020). A time-of-arrival estimation algorithm for OFDM signals in indoor multipath environments. Signal Processing, 169, 107375.

12. Bialer, O., Raphaeli, D., \& Weiss, A. J. (2020). Unsynchronized OFDM network positioning in multipath. Signal Processing, 168, 107344.

13. Babich, F., Noschese, M., Marshall, C., Driusso, M. (2017). A simple method for ToA estimation in OFDM systems. In 2017 European Navigation Conference (ENC), pp. 305-310.

14. Lee, J.-Y., Choi, J.-W., Lee, J.-H., Yoon, J.-M., \& Kim, S.-C. (2018). Enhanced path detection based on interference cancellation for range estimation of communication-based positioning system in indoor environment. IEEE Access, 7, 1658-1667. 
15. Sertatıl, C., Altınkaya, M. A., \& Raoof, K. (2012). A novel acoustic indoor localization system employing CDMA. Digital Signal Processing, 22(3), 506-517.

16. Shin, D.-H., \& Sung, T.-K. (2002). Comparisons of error characteristics between TOA and TDOA positioning. IEEE Transactions on Aerospace and Electronic Systems, 38(1), 307-311.

17. Obeidat, H., Shuaieb, W., Obeidat, O., and Abd-Alhameed, R. (2021). A review of indoor localization techniques and wireless technologies. Wireless Personal Communications. pp. 1-39.

18. Obeidat, H. A. N., et al. (2016). A comparison between vector algorithm and CRSS algorithms for indoor localization using received signal strength. Applied Computational Electromagnetics Society Journal, 31(8), 868-876.

19. Patwari, N., Ash, J. N., Kyperountas, S., Hero, A. O., Moses, R. L., \& Correal, N. S. (2005). Locating the nodes: Cooperative localization in wireless sensor networks. IEEE Signal Processing Magazine, 22(4), 54-69.

20. Zekavat, R. and Buehrer, R. M. (2011). Handbook of position location: Theory, practice and advances, vol. 27, Wiley.

21. Gao, C., Wang,G., and Razul, S. G. (2017). Comparisons of the super-resolution TOA/TDOA estimation algorithms. In 2017 Progress in Electromagnetics Research Symposium-Fall (PIERSFALL), 2017, pp. 2752-2758.

22. Gezici, S., \& Poor, H. V. (2009). Position estimation via ultra-wide-band signals. Proceedings of the IEEE, 97(2), 386-403.

23. Alarifi, A., et al. (2016). Ultra wideband indoor positioning technologies: Analysis and recent advances. Sensors, 16(5), 707.

24. Ohlemueller, T., Winkler, F., and Grass, E. (2010). Radio localization in OFDM networks using the 'round trip phase. In 2010 7th Workshop on Positioning, Navigation and Communication, pp. 23-27.

25. Stryhalyuk, B., Yaremko, O., Maksymyuk, T., \& Melnyk, O. (2012). Performance-increasing method of a wireless system based on determination of time-frequency localization properties of OFDM signal. ECONTECHMOD: An International Quarterly Journal on Economics of Technology and Modelling Processes, 1, 49-54.

26. Tabaghi, P., Dokmanić, I., \& Vetterli, M. (2019). Kinetic euclidean distance matrices. IEEE Transactions on Signal Processing, 68, 452-465.

27. Remcom (2017). Wireless InSite Reference Manual, 3.1.0. Pennsylvania: Remcom.

28. Medeđović, P., Veletić, M. and Blagojević, Ž. (2012). Wireless insite software verification via analysis and comparison of simulation and measurement results. In 2012 Proceedings of the 35th International Convention MIPRO, 2012, pp. 776-781.

29. Dama, Y. A. S., Abd-Alhameed, R. A., Salazar-Quinonez, F., Zhou, D., Jones, S. M. R., and Gao, S. (2011). MIMO indoor propagation prediction using 3D shoot-and-bounce ray (SBR) tracing technique for $2.4 \mathrm{GHz}$ and $5 \mathrm{GHz}$. In Proceedings of the 5th European Conference on Antennas and Propagation (EUCAP), pp. 1655-1658.

Publisher's Note Springer Nature remains neutral with regard to jurisdictional claims in published maps and institutional affiliations.

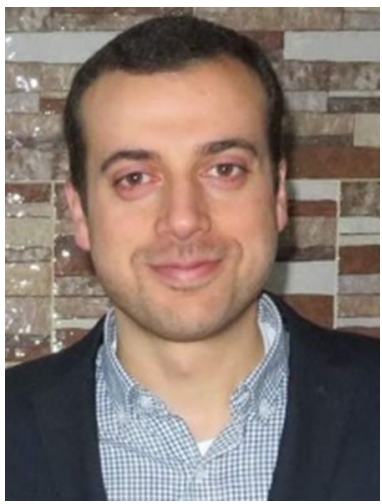

Huthaifa Obeidat is Assistant Professor at Communication and Electronics department at Jerash University in Jordan, he received the PhD in Electrical Engineering from the University of Bradford, UK, in 2018, he was awarded MSc degree in Personal Mobile and Satellite Communication from the same University in 2013. His research interests include Radiowave Propagation, millimetre wave propagation, e-health applications, Antenna and Location-Based Services. Obeidat has been a member of the Jordanian engineering association since 2011. 

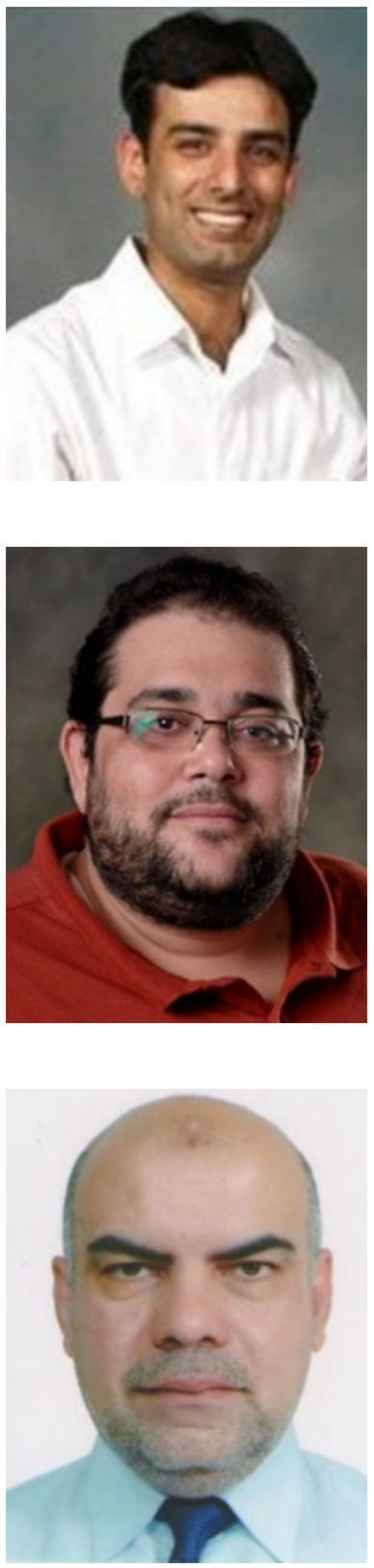

Imran Ahmad is a Research Associate \& Electronic Design Engineer at University of Bradford, he received the MPhil in Applied Electromagnetics and Electronics from the University of Bradford, UK, in 2020. Currently, he serves Antennas and Applied Electromagnetic research group at the Electronics, Communications and Information Systems Engineering (ECISE) as a research associate.

Mohammad R. Rawashdeh is currently an assistant professor in the Telecommunications Engineering Department, Yarmouk University, Irbid, Jordan. He got his Ph.D. from Michigan State University, East Lansing, Michigan, USA in 2018. His research interests include computational electromagnetics, microwave circuits design and analysis, non-destructive evaluation, multiple-criteria decision analysis, and inverse problems. Dr. Rawashdeh is an IEEE member.

Ali Alabdullah is currently pursuing the $\mathrm{PhD}$ degree in Electrical Engineering with the Faculty of Engineering and Informatics, University of Bradford, Bradford, UK. His research interests include emerging technologies for $5 \mathrm{G}$ Wireless Communication System including Adaptive Beamforming Algorithms for wireless networks, Muti-User Massive MIMO. 


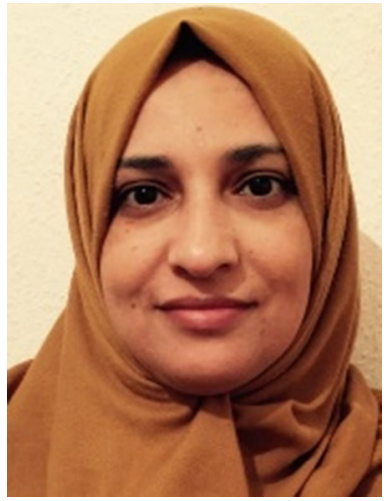

Wafa Shuaieb was born in Elbida, Libya. She received the B.Eng. degree in electronics and electrical engineering from Omar Almukhtar University, Elbida, Libya in 2008 and M.Sc. in electrical and electronics engineering from Alexandria, Egypt, in 2010 and $\mathrm{PhD}$ in Electrical Engineering from University of Bradford in 2018. She has been a research student in the cryptography and use biometric traits in the generation of private keys in public cryptosystem in 2012 and she worked as assistant lecturer at electronic department in Omar Almukhtar University. She is currently working toward the $\mathrm{PhD}$ degree. Her research focus includes direction of arrival, includes location based services methodologies such as angle of arrival.

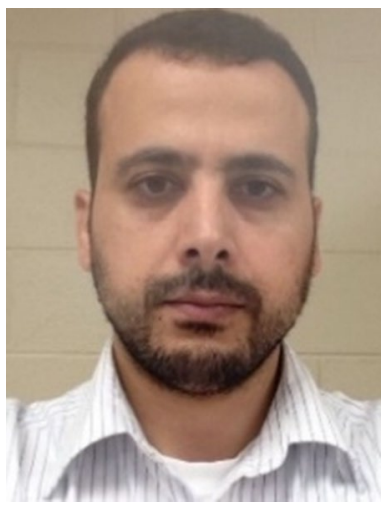

Omar Obeidat received his BSc degree in Electrical Engineering from Jordan University of Science andTechnology 2006, in 2009 he was awarded MSc degree in Wireless Communication engineering from Al -Yarmouk University. He is a $\mathrm{PhD}$ Candidate at Wayne State University. His research interests include Nondestructiveevaluation, thermal imaging and indoor localization services.

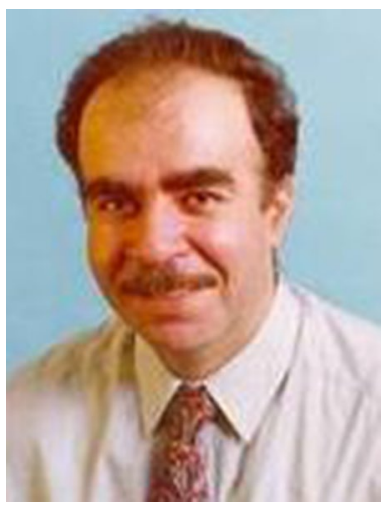

Raed Abd-Alhameed (M'02SM'13) is currently a Professor of electromagnetic and radiofrequencyengineering with the University of Bradford, U.K. He is also the Leader of radiofrequency, propagation, sensordesign, and signal processing; in addition to leading the Communications Research Group for years within theSchool of Engineering and Informatics, University of Bradford. He has long years' research experience in theareas of radio frequency, signal processing, propagations, antennas, and electromagnetic computational techniques. He haspublished over 600 academic journal and conference papers; in addition, he has co-authored four books and several book chapters.He is a principal investigator for several funded applications to EPSRCs and the leader of several successful knowledge TransferProgrammes, such as with Arris (previously known as Pace plc), Yorkshire Water plc, Harvard Engineering plc, IETG Ltd., SevenTechnologies Group, Emkay Ltd., and TwoWorld Ltd. He was a recipient of the Business Innovation Award for his successfulKTP with Pace and Datong companies on the design and implementation of MIMO sensor systems and antenna array design forservice localizations. He is the chair of several successful workshops on energy-efficient and reconfigurable transceivers: Approachtoward Energy Conservation and CO2 Reduction that addresses the biggest challenges for the future wireless systems. He has beena Guest Editor of IET Science, Measurements and Technology Journal since 2009. His interest in computational methods andoptimizations, wireless and mobile communications, sensor design, EMC, beam steering antennas, energy-efficient PAs, and RFpredistorter design applications. He is a fellow of the Institution of Engineering and Technology and a fellow of the HigherEducation Academy and a Chartered Engineer. 